\title{
Synthesis of Novel Y-type Nonlinear Optical Polyesters with Enhanced Thermal Stability of Dipole Alignment
}

\author{
Han-Na Jang and Ju-Yeon Lee \\ Institute of Basic Science, Deparment of Chemistry, Inje Lniversity, Gimhae 621-749, Korea \\ E-mail: chemliainjeackr \\ Received January 21, 2008
}

\begin{abstract}
2.4-Di-(2'-hydroxyethoxy')benzy lidenemalononitrile (3) was prepared and polymerized with terephthaloyl chloride and adipoyl chloride to yield novel Y-type polyesters $\boldsymbol{4}$ and $\mathbf{5}$ containing dioxybenzylidenemalononitrile groups as NLO-chromophores. which constituted parts of the polymer backbone. The resulting polymers $\mathbf{4}$ and $\mathbf{5}$ are soluble in common organic solvents such as acetone and $\mathrm{N}, \mathrm{A}$-dimethylfonnamide. Polymers $\mathbf{4}$ and 5 showed thermal stability up to $300^{\circ} \mathrm{C}$ in thermogravimetric analysis with glass-transition temperatures obtained from differential scanning calorimetry in the range $83-94^{\circ} \mathrm{C}$. The second hanmonic generation (SHG) coefficients $\left(d_{33}\right)$ of poled polymer films at the $1064 \mathrm{~nm}$ fundamental wavelength were around $6.48 \times 10^{-9} \mathrm{esu}$. The dipole alignment exhibited high thernal stability even at $10^{\circ} \mathrm{C}$ higher than ${ }_{g} g$ and no significant $\mathrm{SHG}$ decay was observed below $105^{\circ} \mathrm{C}$ partially due to the main-chain character of polymer structure, which is acceptable for NLO device applications.
\end{abstract}

Key Words : Nonlinear optics. Polyester, AFM. Second harmonic generation. Dipole aligument

\section{Introduction}

Functional materials of nonlinear optical (NLO) activities have been extensively studied over the past decade because of their potential applications in the field of telecommunications. optical switching. etc. ${ }^{\text {T }}$ The organic materials seem to be superior because of their higher nonlinear optical activity and faster response time than the inorganic ones. Among the organic materials the NLO polymers are receiving great attention. mainly because they offer many advantages such as light weight and good processability to form electro-optic devices. ${ }^{23}$ A potential NLO polymer must contain highly polarizable conjugated electronic systems and they have to be mechanically very strong and themally stable. In the developments of NLO polymers for electrooptic device applications. stabilization of electrically induced dipole alignment is one of important criteria. Two approaches have been proposed to minimize the randomization of dipole alignment. One is to use cross-linked system ${ }^{4-7}$ and the other is to utilize high glass-transition temperature $\left(I_{g}\right)$ polymers such as polyimides. ${ }^{8}$ Various polyesters with the NLO-chromophores in the main chain or in side chain ${ }^{10.11}$ were prepared and their properties have been investigated. Generally main-chain NLO polymers have good thermal stability of dipole aliguments. but they often do not dissolve in organic solvents. and their intractability make them unusable to fabricate stable noncentrosymmetric films. On the other hand. side-chain NLO polymer sy'stems have the advantages such as good solubility. homogeneity and high loading level of NLO chromophore. but they often suffer from poor stability of dipole alignments at high temperatures. Recently we have prepared novel NLO polyesters ${ }^{13-14}$ with enhanced thermal stability of dipole alignment by modification of polymer structure. (a)

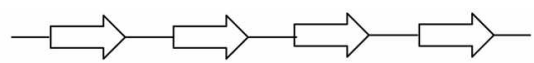

(b)

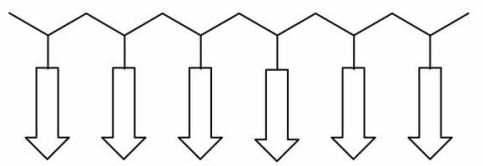

(c)

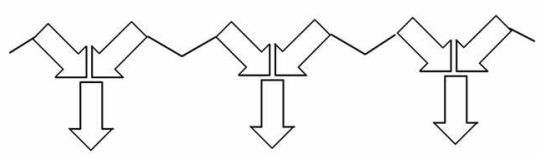

Figure 1. (a) Main-chain NLO polymers, (b) side-chain NLO polymers, and (c) Y-type NLO polymers.

In this work we prepared novel polyesters containing 2.4dioxybenzylidenemalononitrile groups as NLO-chromophores. We selected the latter because they have a large dipole moment and are rather easy to synthesize. Furthermore. 24-dioxybenzylidenemalononitrile groups constitute novel Y-type NLO polyesters (Fig. lc). and these Y-type NLO polyesters have not yet been reported in the literature. Thus. we synthesized a new type of NLO polyester. in which the pendant NLO chromophores are parts of the polymer backbone. These mid-type ${ }^{15}$ NLO polymers are expected to have the advantages of both main-chain and side-chain NLO polymers: stabilization of dipole alignment and good solubility. After confinming the structure of the resulting polymers we investigated their properties such as thennal stability. surface morphology of polymer films. second harmonic generation (SHG) activity and relaxation of dipole alignment.

\section{Results and Discussion}

Synthesis and Characterization of Polymers 4 and 5. 


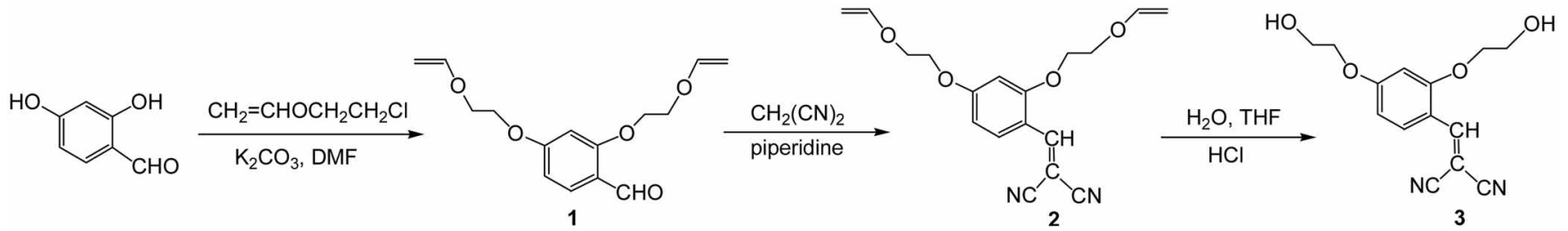

Scheme 1. Synthetic scheme and structure of diol 3

2,4-Di-(2'-vinyloxyethoxy)benzaldelyde (1) was prepared by the reaction of 2-chloroethyl vinyl ether with 2.4dilydroxybenaldehyde. 2,4-Di-(2'-vinyloxyethoxy)benzylidenenalononitrile (2) was prepared by the condensation reaction of 1 with malononitrile. Compound 2 was hydrolyzed to yield acetaldehyde and diol 3 . The synthetic route for compound 3 is presented in Scheme 1. Diol 3 was polymerized with terephthaloyl chloride and adipoyl chloride in a dry DMF solvent to yield Y-type polyesters $\boldsymbol{4}$ and 5 containing the NLO-chromophore 2,4-diosybenzylidenemalononitrile group (Scheme 2). Polymerization results are summarized in Table 1. The polymerization yield was 88 $92 \%$. The chemical structures of the resulting polymers were confirmed by ${ }^{1} \mathrm{H}$ NMR. IR spectra. and elemental analysis. Elemental analysis results fit the polymer structures. ' $\mathrm{H}$ NMR spectra of the polymers showed a signal broadening due to polymerization, but the chemical shifts are consistent with the proposed polymer structures. The signal at 2.11$2.36 \mathrm{ppm}$ assigned to the a-proton indicates the formation of ester linkage. The IR spectra of the same polymer samples also show a strong carbonyl peak near $1722-1724 \mathrm{~cm}^{-1}$ indicating the presence of ester bond. The same polymer samples also show a strong nitrile peak near $2224 \mathrm{~cm}^{-1}$. These results are consistent with the proposed structures, indicating that the NLO-chromophore remained intact during the polymerization. The molecular weights were determined by GPC using polystyrene as the standard and THF as eluent. The number average molecular weight $\left(M_{n}\right)$ of the polymers was determined to be $17200\left(M_{\mathrm{w}} / M_{\mathrm{n}}=1.92\right)$ for polymer $\downarrow$. Polydispersities were in the range 1.89-2.03. The structural feature of these polymers is that they have pendant NLO chromophores, which are parts of the polymer main chains. Thus the resulting polymers (4-5) are mid type of side chain- and main chain NLO polymers, and are expected to have both of their merits. The polymers 4 and 5 were soluble in common solvents such as acetone. DMF, and DMSO. but were not soluble in methanol and diethyl ether. Polymers $\boldsymbol{4}$ and $\mathbf{5}$ isolated from methanol were yellow colored amorphous materials. The inherent viscosities were in the range $0.26-0.30 \mathrm{dL} / \mathrm{g}$. Polymers + and 5 showed strong absorption near $377 \mathrm{rum}$ by the NLO-chromophore 2.4dioxybenzylidenemalononitrile group. We now have well defined polyesters (4-5) and investigate their properties.

Thermal Properties of the Polymers. The thernal beha-

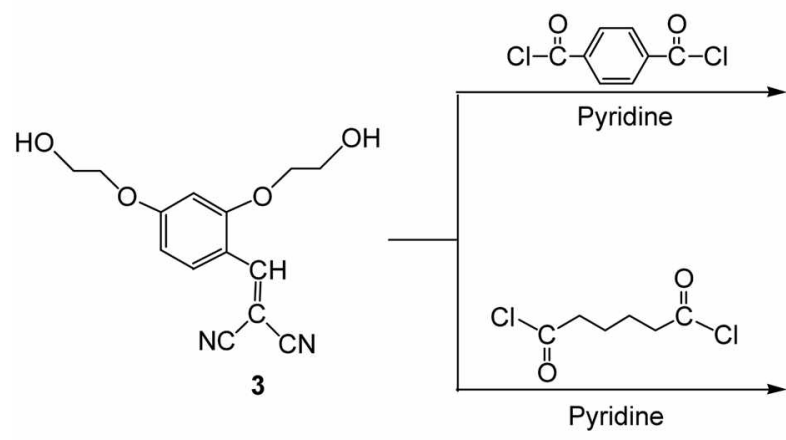<smiles>CCC(=O)c1ccc(C(=O)OCCOc2cc(OCCOC(C)C)ccc2C=C(C#N)C#N)cc1</smiles>

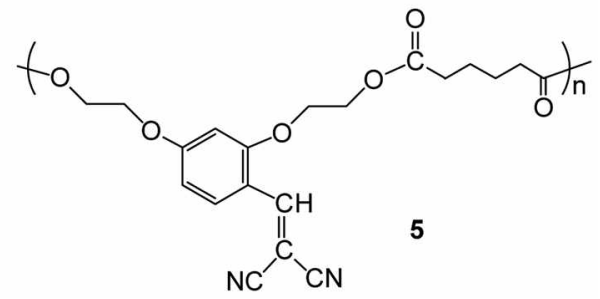

Scheme 2. Synthetic scheme and structures of polymers 4 and 5

Table 1. Polymerization of 3 with TPC and APC in Pyridine

\begin{tabular}{|c|c|c|c|c|c|c|c|c|}
\hline Monomer & $\begin{array}{c}\text { Monomer/Sovent } \\
(\text { mol/l) }\end{array}$ & $\begin{array}{c}\text { Diol } 3 \text { to } \mathrm{R}(\mathrm{COCl})= \\
(\mathrm{m} 1 \mathrm{l} / \mathrm{l} / \mathrm{nol})\end{array}$ & Time (h) & Yield $(\%)$ & $\eta_{\| u l^{d}}(\mathrm{dL} / \mathrm{g})$ & $H_{\mathrm{t}}{ }^{\mathrm{e}}$ & $M_{w}^{e}$ & $\mathrm{PD}^{f}$ \\
\hline 3, TPC & 0.67 & 1.0 & 10 & 90 & 0.30 & 17200 & 33100 & 1.92 \\
\hline 3, TPC & 0.80 & 1.0 & 12 & 92 & 0.29 & 17800 & 33600 & 1.89 \\
\hline 3, APC & 0.67 & 1.0 & 10 & 88 & 0.28 & 17600 & 34400 & 1.95 \\
\hline 3, APC & 0.80 & 1.0 & 12 & 90 & 0.29 & 18500 & 37600 & 2.03 \\
\hline
\end{tabular}

$" 3=2,4$-Di-(2'-hydroxyethoxy)benzylidenemalononitrile. ${ }^{~} \mathrm{TPC}=$ Terephthaloyl chloride. ${ }^{\mathrm{A}} \mathrm{APC}=$ Adipoyl chloride, ${ }^{d}$ Inherent viscosity of polymer: Concentration of $0.5 \mathrm{~g} \mathrm{dL}$ in DMSO at $25^{\circ} \mathrm{C}$. ${ }^{\circ}$ Measured by GPC in THF using polystyrene standard. $\mathrm{PD}=\mathrm{Polydispersity.}$ 
Table 2. Thenmal Properties of Polymers 4 and 5

\begin{tabular}{|c|c|c|c|c|c|c|}
\hline \multirow{2}{*}{ Polymer } & \multirow{2}{*}{$T_{g}{ }^{a}\left({ }^{n} \mathrm{C}\right)$} & \multicolumn{4}{|c|}{ Degradation temp $\left({ }^{\circ} \mathrm{C}\right)^{b}$} & \multirow{2}{*}{ Residue at $800^{\circ} \mathrm{C}(\%)^{b}$} \\
\hline & & Initial-loss & $5 \%$-loss & $20 \%$-loss & $40 \%$ loss & \\
\hline 4 & 94 & 276 & 308 & 396 & 465 & 42.6 \\
\hline 5 & 83 & 272 & 306 & 385 & 458 & 40.4 \\
\hline
\end{tabular}

"Determined from DSC curtes measured on a TA 2920 differential scanning calorimeter with a heating rate of 10 "C:min under nitrogen atmospliere

${ }^{5}$ Detemined from TGA curves measured on a DuPont 951 thermogravimetric analyzer with a heating rate of $10^{\circ} \mathrm{C}$ min under nitrogen atmosphere.

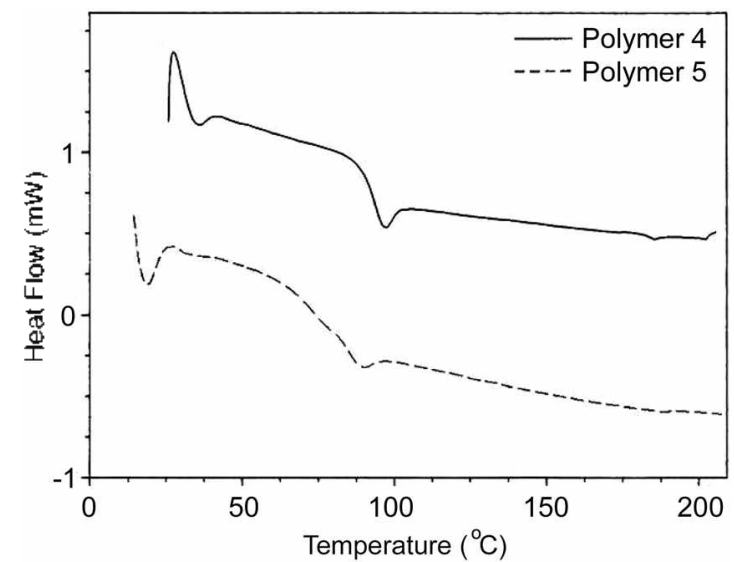

Figure 2. DSC themograms of polymers 4 and 5 at a heating rate of $10^{\circ} \mathrm{C} / \mathrm{min}$ under nitrogen.

vior of the polymers was investigated by thermogravimetric analysis (TGA) and differential scanning calorimeter (DSC) to determine the thermal degradation pattern and glass transition temperature $\left(T_{g}\right)$. The results are summarized in Table 2. DSC thermograms of polymers 4 and 5 are presented in Figure 2. Polymers $\boldsymbol{4}$ and 5 showed a thernal stability up to $300^{\circ} \mathrm{C}$ according to their TGA thermograms. The $T_{g}$ values of the polymers 4 and 5 measured by DSC were in the range $83-94^{\circ} \mathrm{C}$. The TGA and DSC studies showed that the decomposition temperature of the polyesters 4 and 5 was higher than the corresponding $T_{g}$. This indicates that high-temperature poling for a short term is feasible without damaging the NLO chromophore.

Nonlinear Optical Properties of the Polymers. The NLO properties of polymers were studied by the SHG method. To induce noncentrosymmetric polar order. the spin-coated polymer films were corona-poled. As the temperature was raised gradually to $5-10^{\circ} \mathrm{C}$ higher than $T_{\mathrm{g}}$. $6.5 \mathrm{kV}$ of corona voltage was applied and kept at that temperature for $30 \mathrm{~min}$. The poling was confirmed by UVVis spectra. Figure 3 shows the UV-Vis absorption spectra of the polymer 5 before and after poling. Polymers 4 and 5 showed strong absorption near $377 \mathrm{~nm}$ by the NLO-chromophore 2.4-dioxy benzylidenemalononitrile group. After electric poling. the dipole moments of the NLO-chromophores were aligned and the UV-Vis spectrum of polymer $\mathbf{5}$ exhibited a decrease in absorption due to birefringence. From the absorbance change. the order parameter of the poled film could be estimated. which is related to the poling efficiency. The estimated order parameter value $\Phi$ was equal to 0.20 for polymer $5\left(\Phi=1-A_{1} / A_{i}\right.$, where $A_{i j}$ and $A_{1}$ are

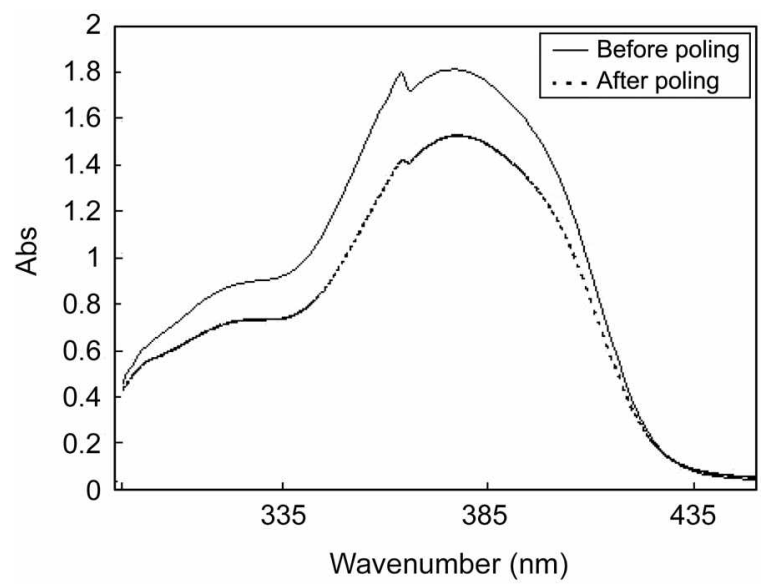

Figure 3. UV-VIs absorption spectrá of a film of polymer 5 before and after poling.

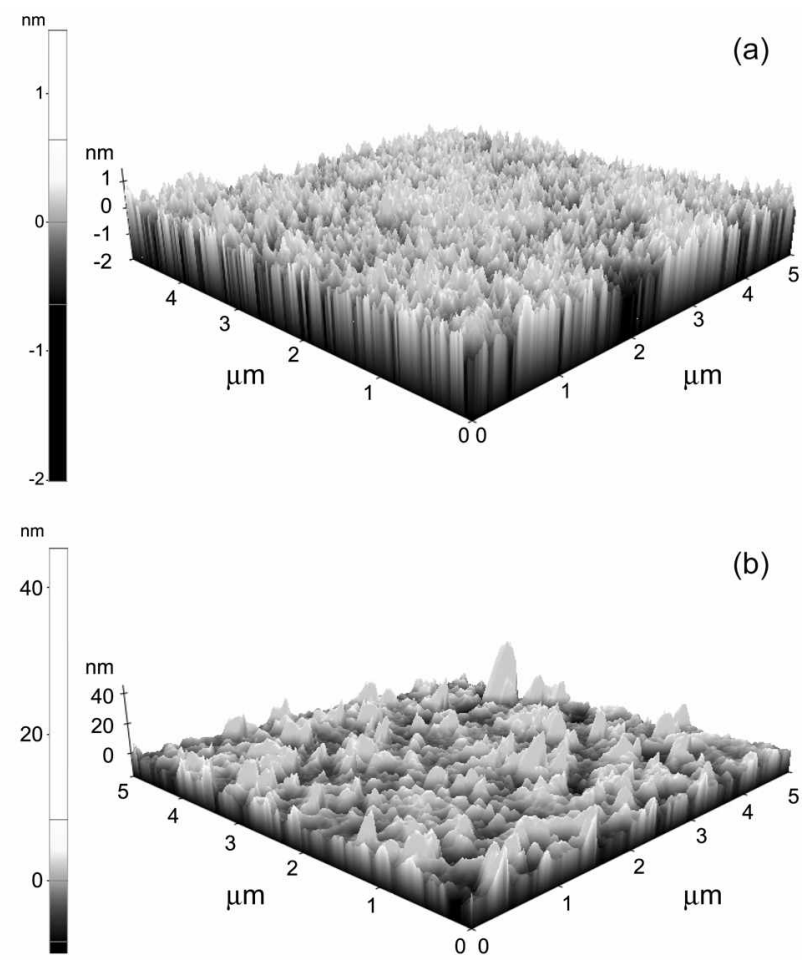

Figure 4. AFM images of spin-coated film of polymer 5 : (a) betore corona-poling; (b) after corona-poling.

the absorbances of the polymer film before and after poling. respectively). For the purpose of investigating surface morphology of polymer films. domain structures of NLOchromophores for the thin-film samples were obtained using atomic force microscopy (AFM). Figure 4 shows AFM scans 


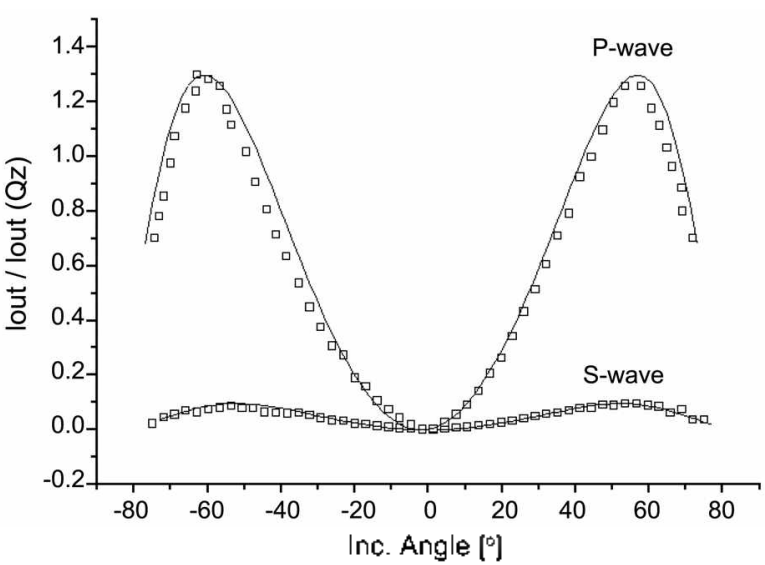

Figure 5. Angular dependence of SHG signal in a poled tilm of polymer 5 .

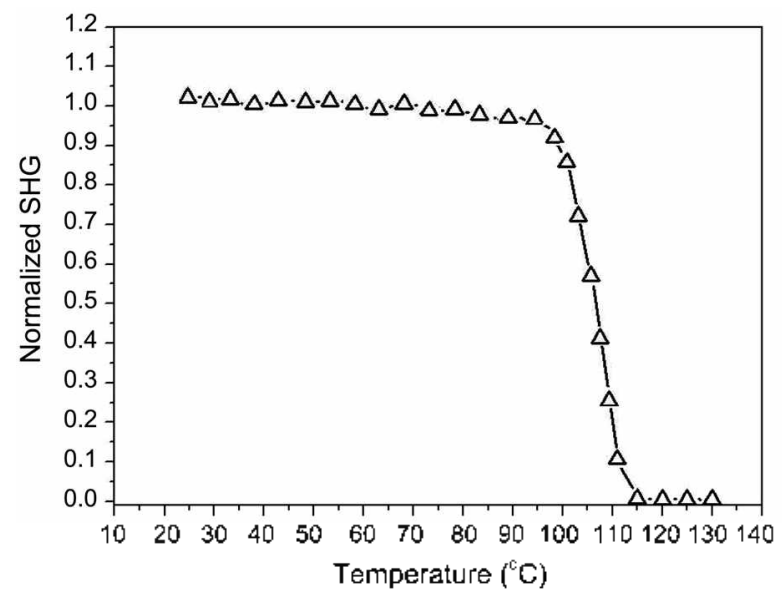

Figure 6. Nonnalized SHG signal of polymer 5 as a function of temperature at a heating rate of $10^{\circ} \mathrm{C} / \mathrm{min}$.

of the spin-coated film before and after poling for polymer $\mathbf{5}$. AFM images show that the surface of the film sample is extremely flat and clean before poling (see Fig. 4a). However. this good quality film was dramatically changed after poling. resulting in numerous hills and valley's in the surface structure. which means that the NLO-chromophores are aligned the poling direction as shown in Figure $4 \mathrm{~b}$. The refractive index of the sample was measured by the optical transmission technique ${ }^{16}$ The transmittance of thin film includes information on the thickness, refractive index and its extinction coefficient. Thus, we can determine those parameters by analyzing the transmittance. SHG measurements were performed at a fundamental wavelength of $1064 \mathrm{~nm}$ using a mode locked Nd-YAG laser. In order to determine the microscopic second-order susceptibility of the polymers, the angular SHG dependence was recorded. Figure 5 shows the angular dependence of SHG signal in a poled polymer 5 . The SHG values were compared with those obtained from a Y-cut quartz plate. To calculate the $d_{31}$ and $d_{33}$ values. both $\mathrm{s}$ polarized and $p$-polarized IR laser were directed to the samples and recorded. Nonlinear optical properties of polymers $\boldsymbol{t}$ and $\mathbf{5}$ are summarized in Table 3. SHG coefficients $\left(d_{3}\right)$ were derived from the analysis of measured Makerfringes with the Pascal fitting program according to the literature procedure. ${ }^{17}$ The values of $d_{31}$ and $d_{33}$ for polymer + were $2.21 \times 10^{-9}$ esu and $6.48 \times 10^{-9}$ esu, respectively. Since the second harmonic wavelength was at $532 \mathrm{~nm}$. which is not in the absorptive region of the resulting polymer. there was not resonant contribution to this $d_{33}$ value. In the isotropic model, the ratio of $d_{3} / d_{31}$ is predicted to be about 3 . Our $d_{33} / d_{31}$ value of 2.93 is in good agreement with the predicted value.

To evaluate the high-temperature stability of the polymers, we studied the temporal stability of the SHG signal. In Figure 6 , we present the dynamic themmal stability study of the NLO activity of the film $\mathbf{5}$. To investigate the real time NLO decay of the SHG signal of the poled polymer films as a function of temperature. in situ SHG measurements were performed at a heating rate of $10^{\circ} \mathrm{C} / \mathrm{min}$ from 30 to $150^{\circ} \mathrm{C}$. The polymer thin film exhibited a thermal stability even at $10{ }^{\circ} \mathrm{C}$ higher than $\%_{y}$ and no significant $\mathrm{SHG}$ decay was observed below $95^{\circ} \mathrm{C}$ for polymer 5 . In general. side-chain NLO polymers lose thermal stability of dipole alignment below 1\%. Stabilization of dipole aligiment is a characteristic of main chain NLO polymers. The exceptional high thermal stability of second harmonic generation of polymers 4 and 5 was due to the stabilization of dipole aligmment of NLO chromophore, which stemmed from the partial main chain character of the polymer structure. The polymers also showed good long-term thermal stability of $d_{33}$ except for the small activity loss within a few days after poling. which are acceptable for NLO device applications. Thus, we obtained a new type of NLO polyester having the advantages of both main-chain and side-chain NLO polymers: stabilization of dipole alignment and good solubility.

\section{Conclusions}

We synthesized novel Y-type polyesters $\mathbf{4}$ and $\mathbf{5}$ with pendant NLO chromophores. which were parts of the

Table 3. Nonlinear Optical Properties of Polymers 4 and 5

\begin{tabular}{|c|c|c|c|c|c|c|}
\hline Polyner & $\lambda_{\max } "(11 \mathrm{~m})$ & $d z^{*}$ (esu) & $\Phi^{c}$ & film thickness ${ }^{d}(\mathrm{am})$ & $d_{31}{ }^{\prime}(\mathrm{esu})$ & $n$ \\
\hline 4 & 377 & $(6.48 \pm 0.12) \times 10^{-9}$ & 0.19 & 0.53 & $(2.21 \pm 0.08) \times 10^{-9}$ & $\begin{array}{l}\mathrm{n}_{1}=1.57 \\
\mathrm{n}_{2}=1.65\end{array}$ \\
\hline 5 & 378 & $(6.26 \pm 0.11) \times 10^{-9}$ & 0.20 & 0.52 & $(2.15 \pm 0.08) \times 10^{-9}$ & $\begin{array}{l}\mathrm{n}_{1}=1.63 \\
\mathrm{n}_{2}=1.68\end{array}$ \\
\hline
\end{tabular}

"Polymer film. "SHG coefficients $\left(d_{33}\right)$ were derived from the analysis of measured Maker-finges. ${ }^{1 "}$ SHG measurements were perfonned at a fundamental wavelength of $1064 \mathrm{~mm}$ using a mode locked Nd-YAG laser. 'Order parameter $\Phi=1-\mathrm{A}_{l}$ ' $\mathrm{A}_{0}$, where $\mathrm{A}_{n}$ and $\mathrm{A}_{1}$ are the absorbances of the polymer film before and after corona poling. respectively. "Film thichesess was determined by the optical transmission technique. ${ }^{\text {If }}$ 
polymer main chains. These mid-type NLO polyesters are soluble in common organic solvents. The resulting polymers 4 and 5 showed a thermal stability up to $300^{\circ} \mathrm{C}$ from TGA thermogranis with $T_{g}$ values in the range $83-94^{\circ} \mathrm{C}$. The SHG coefficients $\left(d_{33}\right)$ of corona-poled polymer films were around $6.48 \times 10^{-9}$ esu. The striking feature of these polymers is that they exhibit SHG stability even at $10^{\circ} \mathrm{C}$ higher than $T_{g}$ and no SHG decay was observed below $105^{\circ} \mathrm{C}$. This exceptional high thermal stability of optical nonlinearity stemmed from the stabilization of dipole alignment of the NLO-chromophore. which constituted a part of the polymer backbone. We are now in the process of extending the polymerization system to the synthesis of other type of NLO polymers and the results will be reported elsewhere.

\section{Experimental Section}

Materials. The reagent grade chemicals were purchased from Aldrich and purified by either distillation or recrystallization before use. 2,4-Dihydroxybenzaldehyde and 2 chloroethyl vinyl ether were used as received. Terephthaloyl chloride (TPC) was purified by sublimation under vacuum. Adipoyl chloride (APC) was purified by distillation under reduced pressure. Malononitrile was recrystallized from water and distilled from phosphorus pentoxide. Piperidine was treated with potassium hydroxide and then distilled over barium oxide to remove trace amounts of water. N.N. Dimethylfornamide (DMF) was purified by drying with anlydrous calcium sulfate, followed by distillation under reduced pressure.

Measurements. IR spectra were taken on a Shimadzu FT IR-8201PC infrared spectrophotometer. ${ }^{1} \mathrm{H}$ NMR spectra were obtained on a Varian $300 \mathrm{MHz}$ NMR spectrometer. UV-Vis absorption spectra were measured on a Shimiadzu UV-3100S spectrophotometer. Elemental analyses were performed using a Perkin-Elmer $2400 \mathrm{CHN}$ elemental analyzer. The glass transition temperatures $\left(T_{g}\right)$ were measured on a TA 2920 differential scanning calorimeter in a nitrogen atmosphere. DuPont 951 thermogravimetric analyzer with a heating rate of $10^{\circ} \mathrm{C} / \mathrm{min}$ up to $800^{\circ} \mathrm{C}$ was used for the thermal degradation study of polymers under nitrogen. The number average molecular weight $\left(M_{n}\right)$ and weight average molecular weight $\left(M_{\mathrm{w}}\right)$ of the polymers were estimated by gel permeation chromatography (GPC) (colununs Styragel HR5E4E: solvent THF). Atomic force microscopy (AFM) images were recorded with a Park Science Instnument Autoprobe $\mathrm{CP}$. operated in a contact mode. which measures topography. Melting points were measured with a Buchi 530 melting point apparatus and are corrected. Viscosity values were obtained by using a Cannon-Fenske viscometer.

Film Preparation and SHG Measurement. The polymer film was prepared from a $10 \mathrm{wt} \%$ by weight polymer solution in DMF deposited on an indium-tin oxide (ITO) covered glass. Prior to film casting. the polymer solution was filtered through $0.45 \mu \mathrm{m}$ Teflon ${ }^{\text {is }}{ }^{-}$mentbrane filter. The film was spin cast at room temperature in the range $1000-1200$ $\mathrm{rpm}$. The films were dried for $12 \mathrm{~h}$ under vacuum at $60^{\circ} \mathrm{C}$.
The aligument of the NLO-chromophore of the polymers was carried out by corona poling method. The poling was performed in a wire-to plane geometry under in situ conditions. The discharging wire to plane distance was $10 \mathrm{~mm}$. As the temperature was raised gradually to $5-10^{\circ} \mathrm{C}$ higher than $T_{\xi}$. $6.5 \mathrm{kV}$ of corona voltage was applied and kept that temperature for $30 \mathrm{~min}$. The films were cooled to room temperature in the presence of the electric field. Finally. the electric field was removed. The refractive index of the sample was measured by the optical transmission tecluique. ${ }^{14}$ Second harmonic generation measurement was carried out one day after poling. A continuum PY6I mode-locked Nd:YAG laser ( $\lambda=1064 \mathrm{~lm}$ ) with pulse width of $40 \mathrm{ps}$ and repetition rate of $10 \mathrm{~Hz}$ was used as the fundamental light source and Y-cut quartz was used as reference. A beam splitter and a photodiode were used to compensate for the intensity fluctuations of the fundamental beam $(1064 \mathrm{~nm})$. The polarity of the fundamental laser beam was adjusted using a half-wave plate before it hit the sample. The electric field vector of the incident beam was either parallel ( $p$-polarization) or perpendicular ( $s$-polarization) to the plane of incidence. Only the $p$-polarized $\mathrm{SH}$ beam was made to enter a photomultiplier tube (PMT) by using a prism and a SH pass filter. An analyzer was used to confirm the polarization direction of the SH signal. A poled polymer film was mounted on the rotator coupled to a step motor. The output signals from the photodiode and PMT were detected as a function of the incident angle. A 3-mm-thick Y-cut quartz cry stal (a piece of quartz plate whose plane is perpendicular to the crystalline $y$-axis and the thickness of the plate is $3 \mathrm{~nm}$. and $\mathrm{d}_{11}=0.3$ $\mathrm{pm} / \mathrm{V}$ ) was used as a reference for determining the relative intensities of the SH signals generated from the samples. The Maker Fringe pattern was obtained by measuring the SHG signal at $0.5^{\circ}$ intervals using a rotation stage. SHG coefficients $\left(d_{33}\right)$ were derived from the analysis of measured Maker-fringes. ${ }^{15}$

Preparation of 2,t-(2'-Vinyloxyethoxy)benzaldehyde (1). 2.4-Dihydroxy benzaldehyde (13.8 g. $0.10 \mathrm{~mol})$. anhydrous potassium carbonate $(82.9$ g. $0.60 \mathrm{~mol})$ and 2-iodoethyl vinyl ether $(49.5 \mathrm{~g} .0 .25 \mathrm{~mol})$ were dissolved in $400 \mathrm{~mL}$ of dry DMF under nitrogen. The mixture was refluxed in an oil bath kept at $80^{\circ} \mathrm{C}$ for $15 \mathrm{hr}$ under nitrogen. The resulting solution was cooled to room temperature. diluted with 300 $\mathrm{mL}$ of water. and extracted with $300 \mathrm{~mL}$ of diethyl ether three times. The organic layer was washed with saturated aqueous sodium chloride solution, and dried with anhydrous magnesium sulfate. Rotary evaporation of diethyl ether gave crude product. which was recrystallized from 1-butanol yielded $25.0 \mathrm{~g}$ (yield $90 \%$ ) of pure product 1. M.p.: 68-69 ${ }^{\circ} \mathrm{C}$. ${ }^{1} \mathrm{H}$ NMR (acetone- $\left.d_{6}\right) \delta 4.03-4.35\left(\mathrm{~m}, 12 \mathrm{H} .2 \mathrm{CH}_{2}=, 2\right.$ $-\mathrm{O}-\mathrm{CH}_{2}-\mathrm{CH}_{2}-\mathrm{O}-$ ), $6.50-6.62$ (m, 4H. $2=\mathrm{CH}-\mathrm{O}$ - aromatic), 7.82-7.86 (d, LH. aromatic), 10.35 (s, IH. -CHO). IR (KBr) $3100.3082(\mathrm{w} .=\mathrm{C}-\mathrm{H}), 2954,2875(\mathrm{~m} . \mathrm{C}-\mathrm{H}), 1674$ (vs. $\mathrm{C}=\mathrm{O}$ ). 1615 (vs. $\mathrm{C}=\mathrm{C}$ ). 1575 (s. $\mathrm{C}=\mathrm{C}$ ) $\mathrm{cm}^{-1}$

Preparation of 2,4-Di-(2'-vinyloxyethoxy)benzylidenemalononitrile (2). Piperidine (0.13 g. $1.5 \mathrm{mmol}$ ) was added to a solution of 2.4-di-(2'-vinyloxyethoxy)benzaldehỳde 1 
(8.35 g. $30 \mathrm{mmol}$ ) and malononitrile $(2.18 \mathrm{~g} .33 \mathrm{mmol})$ in $170 \mathrm{~mL}$ of 1 -butanol with stirring at $0^{\circ} \mathrm{C}$ under nitrogen. After stirring for $4 \mathrm{hr}$ at $0^{\circ} \mathrm{C}$, the reaction mixture was cooled to $-10^{\circ} \mathrm{C}$ for crystallization. The product was filtered and washed successively with cold l-butanol $(80 \mathrm{~mL})$. water $(30 \mathrm{~mL})$, and cold l-butanol $(20 \mathrm{~mL})$. The obtained pale yellow product was recrystallized from l-butanol to give $8.81 \mathrm{~g}$ (vield $90 \%$ of $2 . \mathrm{Mp}=70-71{ }^{\circ} \mathrm{C}$. ${ }^{1} \mathrm{H}$ NMR (DMSO- $d_{6}$ ) $\delta 4.02-4.40\left(\mathrm{~m}, 12 \mathrm{H}, 2 \mathrm{CH}=2-\mathrm{O}-\mathrm{CH}_{2}-\mathrm{CH}_{2}-\mathrm{O}-\right), 6.45-6.71$ (m, $4 \mathrm{H}, 2=\mathrm{CH}-\mathrm{O}$ - aromatic). $8.17-8.34$ (t. $2 \mathrm{H}$. aromatic). IR (KBr) 3117.3037 (w. =C.H), 2943, 2887 (n. C-H). 2222 (s. CN). 1611 (s. $\mathrm{C}=\mathrm{C}$ ). 1566 (vs, C=C) $\mathrm{cm}^{-1}$. Anal. Calcd for $\mathrm{C}_{18} \mathrm{H}_{1} \mathrm{~N}_{2} \mathrm{O}_{4}$ : C. 66.25: H. 5.56; N, 8.58. Found: C. 66.38 : H. 5.65: N, 8.46.

Preparation of 2,4-Di-(2'-hydroxyethoxy)benzylidenemalononitrile (3). Aqueous hydrochloric acid ( $1.5 \mathrm{~mol} \mathrm{~L}^{-1}$. $30 \mathrm{~mL}$ ) was slowly added to a solution of 2,4 -di-(2'-vinyloxyethoxy)benzylidenemalononitrile (2) (8.48 g, $0.026 \mathrm{~mol})$ in $60 \mathrm{~mL}$ of dry THF with stirring under nitrogen at $0^{\circ} \mathrm{C}$. The mixture was stirred at $80^{\circ} \mathrm{C}$ for $8 \mathrm{hr}$ under nitrogen. The resulting solution was extracted with diethyl ether $(80 \mathrm{~mL})$ three times. The organic layer was washed successively with saturated sodium clloride, sodium hydrogen carbonate. and water, followed by drying with andydrous magnesium sulfate. Rotary evaporation of diethyl ether gave crude product. The obtained pale yellow product was recrystallized from ethyl acetate to give $6.13 \mathrm{~g}$ (yield $86 \%$ ) of $3 . \mathrm{Mp}=$ 148-149 ${ }^{\circ} \mathrm{C}$. ${ }^{1} \mathrm{H}$ NMR (acetone- $\left.d_{6}\right) \delta$ 2.78-2.84 (m, $2 \mathrm{H}$. $-\mathrm{OH}$ ) $3.87-3.98$ (nt. 4H, $2-\mathrm{CH}_{2}-\mathrm{OH}$ ). 4.18-4.29 (n. 4H, 2 $\left.-\mathrm{O}-\mathrm{CH}_{2}-\right), 6.73-6.82(\mathrm{~m}, 2 \mathrm{H}$. aromatic), 8.18-8.26 (d, IH. aromatic), 8.43 (s, IH. $-\mathrm{Ph}-\mathrm{CH}=$ ). IR (KBr) 3394 (s. O-H). $3043(\mathrm{w} .=\mathrm{C} \cdot \mathrm{H}), 2953(\mathrm{~m} . \mathrm{C} \cdot \mathrm{H}), 2220(\mathrm{~m}, \mathrm{CN}) .1607,1576$ (vs, $\mathrm{C}=\mathrm{C}$ ) $\mathrm{cm}^{-1}$. Anal. Calcd for $\mathrm{C}_{14} \mathrm{H}_{14} \mathrm{~N}_{2} \mathrm{O}_{4}$ : C. $61.31 ; \mathrm{H}$. 5.14: N, 10.21. Found: C, 61.38: H, 5.23; N, 10.12.

Synthesis of Polyesters 4 and 5 . A representative polycondensation procedure was as follows: Terephthaloyl chloride $(2.03 \mathrm{~g}, 0.01 \mathrm{~mol})$ and diol $3(2.74 \mathrm{~g} .0 .01 \mathrm{~mol})$ were dissolved in $30 \mathrm{~mL}$ of anhyrdrous pyridine under nitrogen. The resulting solution was refluxed in an oil bath kept at 80 ${ }^{\circ} \mathrm{C}$ under a nitrogen atmosphere. After heating $20 \mathrm{~h}$ with stirring the resulting polymerization solution was poured into $400 \mathrm{~mL}$ of methanol. The precipitated polymer was collected and reprecipitated from DMSO into methanol. The polymer was further purified by extraction in a Soxhlet extractor with diethyl ether and dried under vacuum. y ielding $3.64 \mathrm{~g}\left(90 \%\right.$ yield) of polymer $4: \eta_{\text {inh }}=0.30 \mathrm{dL} / \mathrm{g}$ (c. $0.5 \mathrm{~g} / \mathrm{dL}$ in DMSO at $25^{\circ} \mathrm{C}$ ). ${ }^{1} \mathrm{H}$ NMR (DMSO- $d_{6}$ ) $\delta$
$4.42-4.56$ (s. $4 \mathrm{H}, 2-\mathrm{CH}_{2}-\mathrm{O}-$ ) $4.58-4.76$ (d. $4 \mathrm{H} .2 \mathrm{Ph}-\mathrm{O}-\mathrm{CH}_{2}-$ ), 6.75-6.95 (m, 2H. aromatic). $7.95-8.13$ (s. 5H. aromatic), $8.17-8.3$ (s. IH. aromatic). IR (KBr) 3040 (w. =C-H). 2959 (m, C-H), 2224 (s. CN). 1722 (vs. C=O). 1608 (s, C=C) $\mathrm{cm}^{-1}$. Anal. Calcd for $\left(\mathrm{C}_{22} \mathrm{H}_{16} \mathrm{~N}_{2} \mathrm{O}_{6}\right)_{n} ; \mathrm{C}, 65.34: \mathrm{H} .3 .99 ; \mathrm{N}$. 6.93. Found: C. $65.42 ;$ H. $3.88:$ N, 6.97. Polymer 5: $\eta_{\text {unh }}=$ $0.28 \mathrm{dL} / \mathrm{g}$ (c. $0.5 \mathrm{~g} / \mathrm{dL}$ in DMSO at $25^{\circ} \mathrm{C}$ ). ${ }^{1} \mathrm{H}$ NMR (DMSO- $c_{6}$ ) $\delta 1.38-1.62$ (s. $4 \mathrm{H}$. $\left.-\mathrm{CH}_{2}-\mathrm{CH}_{2}=\right), 2.11-2.36$ (d, $4 \mathrm{H} .2-\mathrm{CH}_{2}-\mathrm{CO}-$ ), $4.06-4.39$ (d. $8 \mathrm{H} .2-\mathrm{O}-\mathrm{CH}_{2}-\mathrm{CH}_{2}-\mathrm{O}-$ ), 6.75-6.92 (m. $2 \mathrm{H}$, aromatic). 8.17-8.25 (d. 1H. aromatic), 8.36 (s. IH, -Ph-CH=). IR (KBr) 3056 (w, =C-H), 2953 , 2885 (C-H, m). 2223 (s. CN), 1722 (vs, C=O), 1592 (s. $\mathrm{C}=\mathrm{C}) \mathrm{cm}^{-1}$. Anal. Calcd for $\left(\mathrm{C}_{20} \mathrm{H}_{20} \mathrm{~N}_{2} \mathrm{O}_{6}\right)_{n}: \mathrm{C} .62 .49 ; \mathrm{H}$. $5.24 ;$ N, 7.29. Found: C, 62.56; H. 5.32; N, 7.35.

Acknowledgements. This work was supported by the Inje FIRST project of Inje University and partially by the BK21 project of the Ministry of Education and the Korea Research Foundation Grant funded by the Korean Government (MOEHRD. Basic Research Promotion Fund) (KRF-2007313-C00498)

\section{References}

1. Molecular Nonlinear Optics Haterials Plysics and Devices: Zyss J., Ed: Academic Press: Orlando, 1994.

2. Cho. M. J.: Kim, J. Y.: Kim, J. H.; Lee, S. H.; Dalton, L. R.: Choi. D. H. Bull. Konean Chent. Soc. 2005. 26. 77.

3. Lee. C.: Park. S.-K.: Yang. M.: Lee. N.-S.: Kiml. N. J. Bull. Korem Chem. Soc 2007. 28, 447.

4. Han. K. S.: Park. S. K.: Shim, S. Y.: Jahng. W. S.; Kim, N. J. Bull. Korean Chem. Soc. $1998.19,1165$.

5. Han. K. S.; Park, S. K.: Shim. S. Y; Lee, Y. S.: Jahng. W. S.: Kim. N. J. Bull. Korean Chem. Soc. 1998. 19.1168.

6. Cho. B. R.: Kim. Y. H.: Son. K. W.: Khalil. C.: Kim. Y. H.: Teon. S.-T. Bull. Korem Chent Soc. 2002. 23. 1253.

7. Moon. J. R.: Kim, B. S.; Kim, J.-H. Bull Korean Chem. Soc. 2006. 27,981

8. Kim. M. H.: Jin. J.-I; Lee, C. J.: Kim. N. J.: Park, C. H. Bull. Korean Chem. Soc. 2002. 23.964.

9. Lee. T.-H.: Lee. K.-S. Bull. Korean Chem. Soc. 2000. 21.847.

10. Lee. S.-H.: Kiml. Y.-K.: Won1. Y.-H. Macromolectles 1999. 32. 342.

11. Renate. D.: Walter. M. F. F; Dietmar. K.: Hans, J. Dyes and Pignents 1997. 34. 13.

12. Lee. J.-Y.: Jung. W.-T.: Lee. W.-J. Polym Int 2006, 55. 248.

13. Lee. T.Y.: Kim. J.-H.: Won. D.-S.: Tang. H.-N. Bull. Korean Chent. Soc. 2007.28. 1433

14. Won. D.-S.: Lee. G.-Y.: Lee. J.-Y. Dyes and Pigntents 2008 in press

15. Mid-type polymers mean that the polymers have intenmediate structures between side-chain and main-chain polymers.

16. Cisneros, J. I. Appl. Opt. 1998. 37. 5262.

17. Herman. W. N.: Hayden. L. M. J. Opt. Soc. Ant. B 1995. 12.416. 